\title{
Evaluation of Social and Academic Effects of School-wide Positive Behaviour Support in a Canadian School District
}

\author{
Kent Mclntosh \& Joanna L. Bennett \\ University of British Columbia \\ Kathy Price \\ Kamloops-Thompson River School District
}

\begin{abstract}
This article discusses School-wide Positive Behaviour Support (SWPBS), an evidence-based approach to teaching social competencies and enhancing the school social environment. The focus of this article is on the value of evaluation and evaluation plans at a district level for maintaining and increasing the effectiveness of SWPBS in a district. We review the key components of evaluation plans and describe a framework for creating evaluation plans created for British Columbia. We also provide an example of the evaluation efforts using this framework in a medium sized school district in British Columbia. Results showed decreased levels of problem behaviour, decreased numbers of students at risk for significant behaviour challenges, and increased academic achievement and student perceptions of school safety for schools implementing SWPBS, in comparison to low implementing schools and district and provincial averages.
\end{abstract}

Canadian teachers are faced with many challenges in schools, including problem behaviour, violence, and pressure to increase the academic achievement of students (Day, Golench, MacDougal, \& Beals-Gonzalez, 2002). These challenges can hinder the social and academic growth of all students in a school, and many teachers report not being prepared with the necessary tools and strategies to address these issues (Malecki \& Elliot, 2002; Markow, Moessner, \& Horowitz, 2006). Research shows that exclusionary discipline strategies, such as suspension and expulsion, are not effective in reducing challenging behaviours and may even increase the likelihood of their occurrence (Hemphill, Toumbourou, Herrenkohl, McMorris, \& Catalano, 2006; Mayer, 1995). Moreover, reactionary exclusionary discipline is provided disproportionally to students from culturally diverse backgrounds (Skiba, Michael, Nardo, \& Peterson, 2002; Skiba, Peterson, \& Williams, 1997). Rather, a coordinated, systems-level approach for increasing social competency is needed to provide effective support to all students. One approach 
that has been increasingly adopted to address the needs of students is School-wide Positive Behaviour Support (SWPBS).

\section{School-wide Positive Behaviour Support}

SWPBS is a systems-level approach to creating a positive school environment that encourages prosocial interactions and allows effective instruction and learning to take place (Sugai \& Horner, 2009). A primary focus of SWPBS is on preventing problem behaviour through the implementation of evidence-based practices and continuous collection of data to guide decision making (Menendez, Payne, \& Mayton, 2008). As such, SWPBS is not a set program; rather, it is a framework used to select empirically supported interventions to meet the needs of each school. SWPBS is based on a three-tier public health model of prevention; in which universal support is provided to all students; targeted support is provided to those at-risk for challenges; and intensive, individualized support is provided to those with significant challenges (H. M. Walker et al., 1996). As a result, SWPBS is used to support behaviour and learning at the whole-school level and provide increasing levels of support (small group and individual) for students with more intensive needs (Turnbull et al., 2002). The effectiveness of SWPBS in multiple valued domains (e.g., social competence, school safety, academic achievement) makes it an appealing approach, and as such, its implementation in Canadian and U.S. school districts is expanding (Chapman \& Hofweber, 2000).

\section{Critical Features of SWPBS}

The SWPBS approach emphasizes not only practices, but also systems and data (Lewis \& Sugai, 1999). Practices are implemented based on the specific needs and desired outcomes of the school's stakeholders. Systems, such as building leadership teams and district coaching structures, will assist school personnel in fully implementing the practices. Data are used to evaluate the outcomes and guide the implementation and modification of systems and practices.

Practices. Although matched and adapted for each school culture, there are common underlying practices that characterize SWPBS (Lewis \& Sugai, 1999). For instance, a common practice is to identify a small number (i.e., three to five) of positively stated expectations (e.g., be kind, be responsible, be safe). In contrast to a laundry list of prohibited behaviours that emphasize compliance with adult directions, expectations are positively stated to represent social emotional competencies and foundational principles of prosocial behaviour. Once clearly defined, these competencies are explicitly taught to students through specific examples and nonexamples of expectations and practice in different locations around the school (Sugai \& Horner, 2009). Because being responsible in the hallways (e.g., use a quiet voice, walk on the right) may look different from being responsible on the playground (e.g., share equipment, take turns), expectations are taught in each location. To remind students of expected behaviours, posters with the expectations, often created by students, are displayed in classrooms and hallways (McKevitt \& Braaksma, 2008). School personnel regularly acknowledge students for demonstrating expected behaviours using verbal praise and encouragement, often paired with tangible acknowledgement systems (e.g., tickets entered into a draw for school supplies), which serve as a system for staff to increase positive interactions with students (Lewis \& Sugai, 1999).

Systems. To implement and sustain SWPBS, systems are needed to support school personnel in its implementation. Professional development workshops are insufficient support for 
implementing comprehensive school reform like SWPBS (Sugai \& Horner, 2009). Rather, ensuring local capacity for continuous support is necessary. Effective systems include leadership teams, external coaching, training, and communication and collaboration with other schools (Sugai \& Horner, 2009). When in place, these systems meet the needs of school personnel, supporting them in effectively and efficiently using the practices in their schools (Lewis \& Sugai, 1999).

Leadership teams are made up of a representative group of school personnel (e.g., teachers, administrators, and support staff) who have knowledge and interest in SWPBS (McKevitt \& Braaksma, 2008). The leadership team meets regularly to develop and review the school's action plan and review data. External coaches support a number of school teams in the district in the planning and the facilitation of implementation. Finally, collaboration between schools allows schools to share their own success stories and gather ideas and inspiration from others.

Data. Effective action planning for SWPBS relies on continuous collection and evaluation of data (Sugai \& Horner, 2009). By collecting efficient data that do not interfere with instruction, school and district personnel can select and adapt interventions based on ongoing feedback from their school. Data collected at the systems-level includes gathering both quantitative information, such as frequency of office discipline referrals, and qualitative information, such as interviews of teachers and students and informal observations (Turnbull et al., 2002). Based on these data, goals can be created and changes in valued outcomes can be monitored. Interventions can then be selected and adapted based on the data collected (Horner, Sugai, Todd, \& Lewis-Palmer, 2005). The SWPBS implementation process will therefore be unique for each particular school based on the data collected on the needs of students and school personnel.

\section{The Evidence Base for SWPBS}

Research shows that SWPBS is related to a range of student and teacher outcomes. For instance, implementation of SWPBS leads to higher levels of prosocial behaviour and reductions in problem behaviour (Lassen, Steele, \& Sailor, 2006; Nelson, Martella, \& Marchand-Martella, 2002). In a pretest-posttest comparison study, Nelson and colleagues (2002) identified students across grades 1 to 5 in seven schools who displayed high levels of problem behaviour prior to the implementation of SWPBS and monitored their social competence with the Behavioral and Emotional Rating Scale (Epstein \& Sharma, 1998) before and following implementation. After implementation of SWPBS, these students showed statistically significantly improved social competence. Results from this study and others also show that implementing SWPBS decreases the use of exclusionary discipline, such as office discipline referrals and student suspensions, when compared to baseline rates (Lassen et al., 2006; Nelson, 1996; Nelson et al., 2002; Scott, 2001; Taylor-Greene et al., 1997) and increases perceptions of school safety (Horner et al., 2009; Nelson et al., 2002).

The effects of SWPBS also extend beyond prosocial and problem behaviour. A number of studies - including two randomized, wait-list control trials - have shown statistically significant increases in academic achievement, including scores on standardized achievement measures and the percent of students meeting or exceeding expectations on high-stakes state achievement tests, following the implementation of SWPBS (Bradshaw, Mitchell, \& Leaf, 2010; Horner et al., 2009; Lassen et al., 2006; Nelson et al., 2002). In addition to positive outcomes for students, research also indicates that SWPBS is related to positive teacher outcomes such as higher teacher efficacy, the belief that one can enhance student outcomes (Bennett \& McIntosh, 2011; Ross \& 
Horner, 2006). Finally, in a randomized control trial, Bradshaw and colleagues (Bradshaw, Koth, Bevans, Ialongo, \& Leaf, 2008) demonstrated significantly improved scores on the Organizational Health Inventory (Hoy \& Feldman, 1987), a measure of organizational effectiveness and collegial affiliation among staff in schools, with no changes in control schools.

\section{Evaluation of SWPBS Systems}

As with any major systems change initiative, SWPBS takes time to implement and requires careful planning for successful implementation and sustained practice (Chapman \& Hofweber, 2000; George \& Kincaid, 2008). Evaluation is a critical component for the effective implementation of SWPBS. It allows school personnel to ask and answer necessary questions to ensure that the practice is meeting the school's needs and continues to be implemented with fidelity. Evaluation begins prior to implementation, assessing whether the district has the resources and capacity necessary to implement SWPBS with fidelity, and provides schools with data to identify valued outcomes (George \& Kincaid, 2008). Successful evaluation will involve instruments that are efficient and practical to use, providing frequent access to information that will guide decision making (Algozzine et al., 2010). The outcomes of evaluation allow districts to examine the influence of SWPBS and adapt practices to make them more effective, increasing the likelihood of sustainability.

District evaluation plans are valuable tools that provide a district with a formal outline for evaluating whether implementation steps are followed, practices are implemented with fidelity, and valued goals are achieved (George \& Kincaid, 2008). Evaluation plans document what evaluation measures should be used and when to use them and can guide school teams in the interpretation of the outcome data. When evaluation measures are described with instructions for frequency of use and analysis of results, evaluation will be more efficient, reducing the resources needed for completion.

Horner, Sugai, and Lewis-Palmer (2005) created a template to guide SWPBS teams in formulating their own evaluation plans. The template recommends that teams create an evaluation plan that (a) incorporates measures that are valid, reliable, and efficient; (b) provides stakeholders with valued information; and (c) presents evaluation results that are easily understood and provided on a regular basis. In addition, evaluation plans should be organized in such a way that evaluation questions can be used to guide decision making.

\section{The BC PBS Evaluation Framework}

Based on the template by Horner and colleagues (Horner et al., 2005), an evaluation framework for British Columbia (BC) was created in 2008 and was supported by funding from the BC Ministry of Education (McIntosh, 2008). Using the framework, districts can build their own plans for what outcomes to measure and how and when to measure them. The framework provides and describes detailed features of effective evaluation systems, a list of measures that may be utilized for evaluation, a sample matrix that district teams can follow to create and document the evaluation process, and an exemplar plan and report that teams can follow to create their own evaluation reports.

The BC framework delineates three features of effective evaluation systems: evaluation of (a) the process of implementation, (b) the fidelity of implementation, and (c) valued outcomes for students and staff. Teams can use these three broad areas of evaluation to guide them to specific evaluation questions relevant to their district. 
Process. An effective evaluation plan will include steps to evaluate the process of implementation. This part of evaluation involves documenting district action plan goals that have been met, are ongoing, or are future goals; persons involved in fulfilling the goals; and dates of completion or target completion. Evaluating the process also involves assessing the training and support provided for school personnel and district coaches.

Typical evaluation plans will document what steps from the district's action plan that the team have taken, what support was provided (e.g., what training was conducted?, what coaching was available?), who received support (e.g., what schools or school teams received training?, what schools received coaching?), and who provided support (e.g., list of district coaches, local experts). Each question lists the measures used to evaluate the questions, when the information was collected, and the metric used to evaluate effectiveness.

Fidelity of implementation. In addition to evaluating what training and support is in place in the district, it is important to assess to what extent the critical components of SWPBS are implemented with fidelity, that is, that they are implemented as designed (Gresham, 1989). An evaluation plan should include strategies to assess not only the fidelity of implementation of the universal systems of SWPBS, but also the targeted and individual programs that are implemented to support social competence. A variety of research-validated measures are available to schools and district teams to evaluate fidelity of implementation, such as the PBS SelfAssessment Survey (Sugai, Horner, \& Todd, 2000), a survey completed by all school personnel that can be used to evaluate implementation of SWPBS in all parts of the school. After evaluation measures have been chosen and documented in the evaluation plan, the steps of evaluation, such as when information was collected and how results were used, are also documented.

Valued outcomes. Finally, an evaluation plan includes steps to document and assess whether adequate implementation produced valued outcomes. School personnel identify outcomes that are valued by the school and stakeholders prior to implementation of SWPBS. These outcomes are essential to selecting practices and making decisions based on whether the outcomes are being reached. A practice is only valuable to school personnel if it produces outcomes that are valued (McIntosh, Horner, \& Sugai, 2009). Evaluating outcomes allows teams to assess whether to continue or revise practices based on data. Evaluating the changes in outcomes involves two steps. First, changes in outcomes are examined for students, school personnel, and parents over time within each school. Second, changes in outcomes for schools implementing SWPBS with fidelity are compared to schools not implementing SWPBS, schools implementing with poor fidelity, or to district or provincial averages.

Common data that are used to evaluate valued outcomes include office discipline referrals (ODRs), standardized forms that teachers complete to document incidents of problem behaviour that require administrative involvement (e.g., physical aggression, defiance). When standardized (e.g., through common forms, definitions, procedures, and training), these forms provide an efficient and effective measure of overall problem behaviour in the school (Irvin, Tobin, Sprague, Sugai, \& Vincent, 2004). Research has indicated that ODRs have high construct and concurrent validity as a measure of problem behaviour and show stability over time (McIntosh, Campbell, Carter, \& Zumbo, 2009; McIntosh, Frank, \& Spaulding, 2010). Other common outcomes data include student social competence, academic achievement, attendance, and perceptions of school safety. It is worthwhile to consider what data that are already collected on a regular basis may be used to assess outcomes (McIntosh, Reinke, \& Herman, 2009). After 
measures have been selected, guidelines can be formed to outline how and when data will be collected, and what scores would indicate sufficient improvement.

\section{Case Study}

As an illustration of both the process of creating an evaluation plan and the outcomes measured from it, an example is provided from a school district in British Columbia. Following the creation of the $\mathrm{BC}$ evaluation framework, one school district was selected as a provincial demonstration district. The district was chosen because it had been sustaining SWPBS for a number of years, with some schools having sustained SWPBS for over ten years. The district also had strong support from administration, and there was a budget allocated to provide release time and other costs related to evaluation. At the time of evaluation, schools in the district had received ongoing assistance from coaches and a district behaviour consultant team. School personnel were also provided with ongoing opportunities for training in SWPBS. Despite these strengths, the district had not implemented an evaluation plan but was motivated to evaluate the status of SWPBS in their district.

\section{Method}

The demonstration district was a mid-size urban public school district with 49 schools. At the time of evaluation, approximately 15,000 students were enrolled in the district. English was the primary language spoken at home (98\%), and $16 \%$ of students were identified with Aboriginal ancestry. When the evaluation plan was created, 11 elementary (grades K to 7) and one secondary (grades 8 to 12) school were implementing SWPBS, nine of which had been implementing for 5 years or longer. These schools represented $26 \%$ of the schools in the district.

\section{Evaluation of Process}

To examine the process of implementation, the evaluation plan included a number of questions to document what steps the district was taking to grow and sustain SWPBS in the district. The first question focused on action planning at the district level. To document this information, the district leadership team used the Implementers' Blueprint and Self-Assessment (Sugai et al., 2005) twice per year and examined the number of action plan goals that the team had met. The team also recorded which schools were receiving training and technical assistance. Next, the plan documented what SWPBS training had occurred, including the type of training and the school teams that were involved. The perceived usefulness of these events was also evaluated through brief questionnaires completed by attendees after each training event. A list of coaches and how much time they spent at each school per week was also used to evaluate who was providing support to schools, and a coaches' survey and a list of meetings and trainings for coaches was used to evaluate how coaches were supported. Finally, a list of administrator trainings and visits to schools was examined to evaluate the engagement of administrators in the SWPBS initiative.

\section{Evaluation of Fidelity of Implementation}

The year of evaluation was the first year that fidelity of implementation had been formally assessed in the district. The School-wide Evaluation Tool (SET; Sugai, Lewis-Palmer, 
Todd, \& Horner, 2001) was used to assess fidelity of SWPBS implementation in nine schools. The SET is a direct observation tool used to assess the fidelity of PBS implementation. This tool is a research validated measure, with strong evidence of reliability and validity for assessing SWPBS implementation, including internal consistency of .96, test-retest reliability of .97, interrater reliability of .99, correlation with the PBS Self-Assessment Survey of .75, and sensitivity to SWPBS training (Horner et al., 2004). The SET consists of a 2-hour site visit, with interviews of administrators, teachers, and students; direct observation; and a review of permanent products. It is conducted by an external team and was conducted in this evaluation by a research team from the University of British Columbia. The long term goal identified was for all schools to be implementing SWPBS at or above the 80\% SET criterion, which indicates full implementation of the critical features of universal SWPBS.

\section{Evaluation of Valued Outcomes}

To measure school outcomes, the district examined levels of problem behaviour, academic achievement, and student perceptions of school safety. Problem behaviour was measured through ODRs for the nine elementary schools reporting ODR data through the School-wide Information System (SWIS; May et al., 2008), a web-based ODR entry and analysis application. SWIS includes a set of required reliability criteria that must be met before it can be used (e.g., standardized form and definitions, training on discriminating between office and classroommanaged behaviours) - all schools in the study met these criteria.

ODRs were standardized to the number of ODRs per 100 students per day (to account for variations in enrolment and number of school days in the year). The goal for the district was to have ODR rates below normative SWIS averages. Additionally, the percent of students receiving 0 to 1,2 to 5 , and 6 or more total ODRs per year were calculated to indicate the percent of students who were successful with school-wide support, required moderate support, and required intensive support, respectively. These criteria are based on normative data from schools using SWIS (Horner, Sugai, Todd et al., 2005) and have been validated through statistically significant differences in ratings of problem behaviour on the Behavior Assessment Scale for Children 2 (Reynolds \& Kamphaus, 2004) and Social Skills Rating System (Gresham \& Elliott, 1990) at each level of ODRs (McIntosh, Campbell et al., 2009; B. Walker, Cheney, Stage, \& Blum, 2005). The goals set for indicating success included supporting at least $80 \%$ of students with school-wide support (0 to 1 ODRs).

Academic achievement was assessed through the percent of students meeting or exceeding standards on a provincial high-stakes achievement test (the Foundation Skills Assessment). This test is administered to students in grades 4 and 7 in all schools across BC to assess skills in reading comprehension, writing, and numeracy. Internal consistency estimates show evidence of adequate reliability in reading (Grade $4=.88$; Grade $7=.89$ ) and numeracy (Grade $4=.90$; Grade $7=.90$ ), but poor reliability in writing (Grade $4=.57$; Grade $7=.61$; British Columbia Ministry of Education, 2008). Items on the assessment were selected to align with content standards according to the BC Ministry of Education.

Student perceptions of safety were assessed through the Satisfaction Survey, a questionnaire administered as part of the Foundation Skills Assessment to measure their views on their schooling, school climate, and school safety. Three items from this survey were examined as a measure of perceived school safety and climate: (1) Do you feel safe at school?, (2) At school, are you bullied, teased, or picked on?, and (3) Do you know how your school expects students to behave? These items were created through reviews of existing measures and in consultation with 
teachers and educational researchers. The BC Ministry of Education has reported that analyses have shown that the Satisfaction Survey is a reliable and valid tool for assessing student perceptions of their school environment, though results have not been made publicly available (British Columbia Ministry of Education, 2007).

\section{Results}

\section{Process}

The major training opportunity for the district was a provincial conference, which many school teams attended. In addition, a number of introduction sessions to SWPBS were provided to build awareness and interest, and a district share-fair was planned to establish a community of practice for peer networking. Eight of the 12 schools in the district were supported by five district coaches. Throughout the year, the coaches received training in SWPBS evaluation; an advanced workshop for district trainers and an advanced coaches training were planned for the following year. In addition, coaches received training in conducting the SET in the district. Evaluation of the leadership team showed that the district leadership team completed an annual self-evaluation, and five long-term action plan items were completed that year.

\section{Fidelity of Implementation}

SET results showed that two of the nine schools in the district were assessed to have attained the $80 \%$ criterion and therefore were evaluated to be implementing SWPBS with high fidelity. In addition, another four schools were implementing with moderate fidelity (between $70 \%$ and $79 \%$ ), leaving three schools implementing with low fidelity.

\section{Valued Outcomes}

Results from analyses of problem behaviour are shown in Figures 1 and 2. For the nine elementary schools with ODR data, the average number of ODRs per 100 students per day was .23 , a reduction from .43 in the previous year and below the SWIS average of .34 ODRs per 100 students per day (see Figure 1). In addition, 90\% of students had 0 to 1 ODRs in the year, an increase from $86 \%$ in the previous year and above the goal of $80 \%$. The percent of students indicated as "some risk" (2 to 5 ODRs) and "at risk" (6 or more ODRs) had decreased from 14\% in the previous year to $10 \%$ in the year of the evaluation (see Figure 2).

Results from analyses of academic achievement are shown in Figures 3 (Grade 4) and 4 (Grade 7). The figures show the percent of students who met or exceeded expectations for reading, writing, and math for moderate to high fidelity SWPBS schools, low fidelity SWPBS schools, the district average, and the provincial average. The results show that all scores for moderate to high fidelity SWPBS schools were at or above the results for low fidelity schools for both grades 4 and 7. Academic achievement in moderate to high fidelity SWPBS schools exceeded the district average on four of the six tests, despite having a higher rate of families earning below $\$ 30,000$ per year than both low fidelity schools and the district average.

Student perceptions results (see Figures 5 and 6) show the percent of students who responded "Many times" or "All of the time" to each question. These results show that students in moderate to high fidelity schools reported feeling safer, clearer on what is expected of them, and less bullied than students in low fidelity schools and the district average for both grades 4 and 7 , 


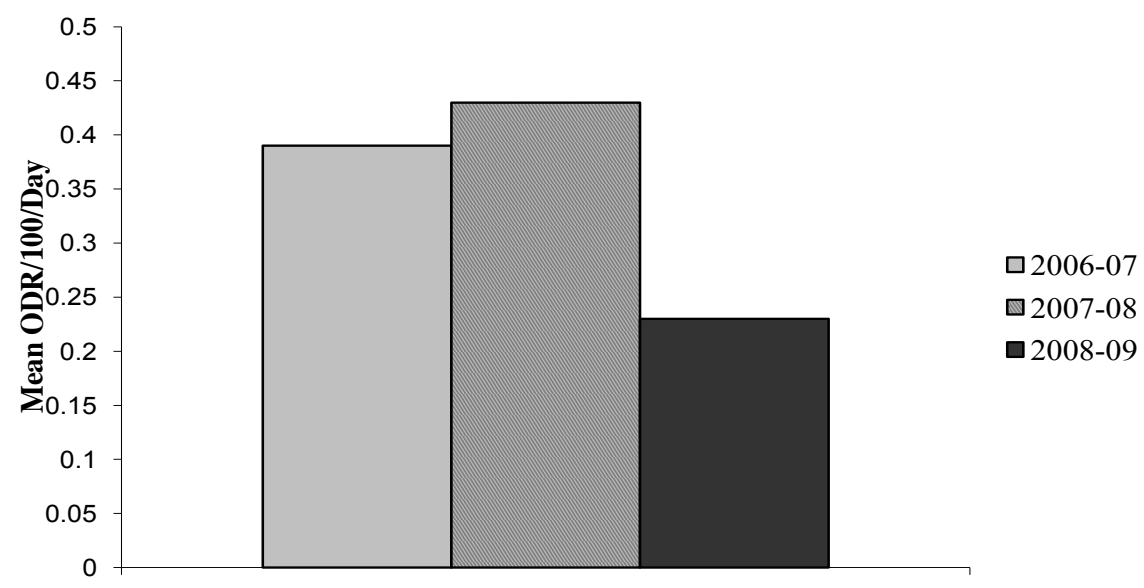

Figure 1. Mean number of Office Discipline Referrals (ODRs) per 100 students per day for nine elementary schools implementing SWPBS over 3 years.

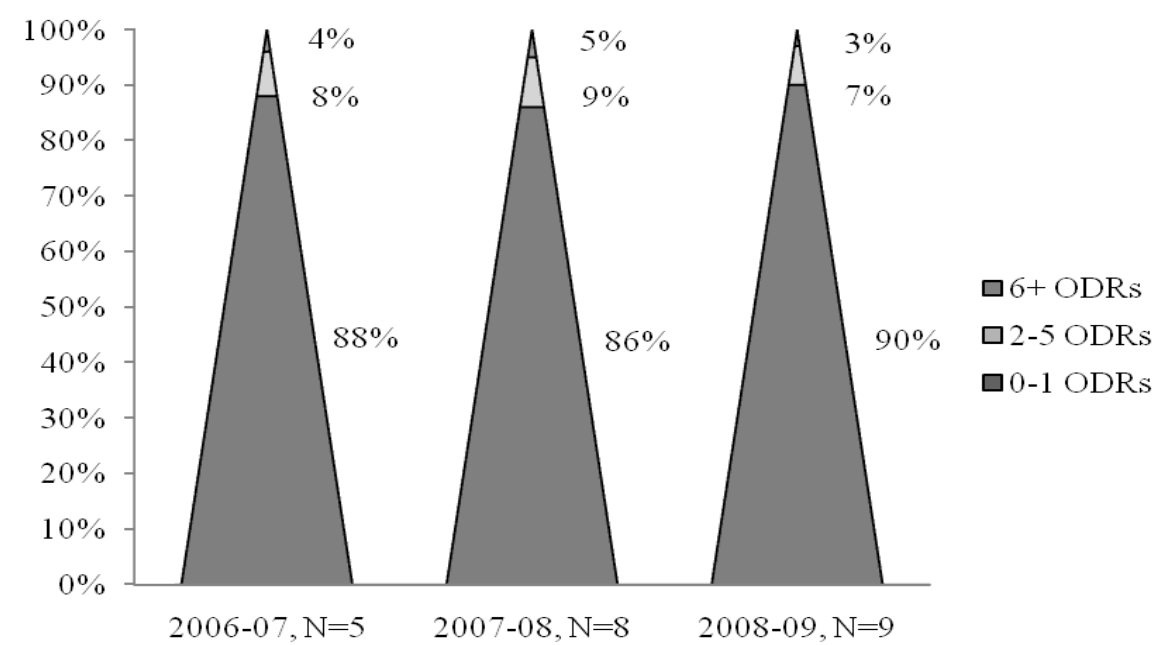

Figure 2. Percent of students who are "low risk" (0-1 ODRs per year), "some risk" (2-5 ODRs per year), and "at risk" (6 or more ODRs per year).

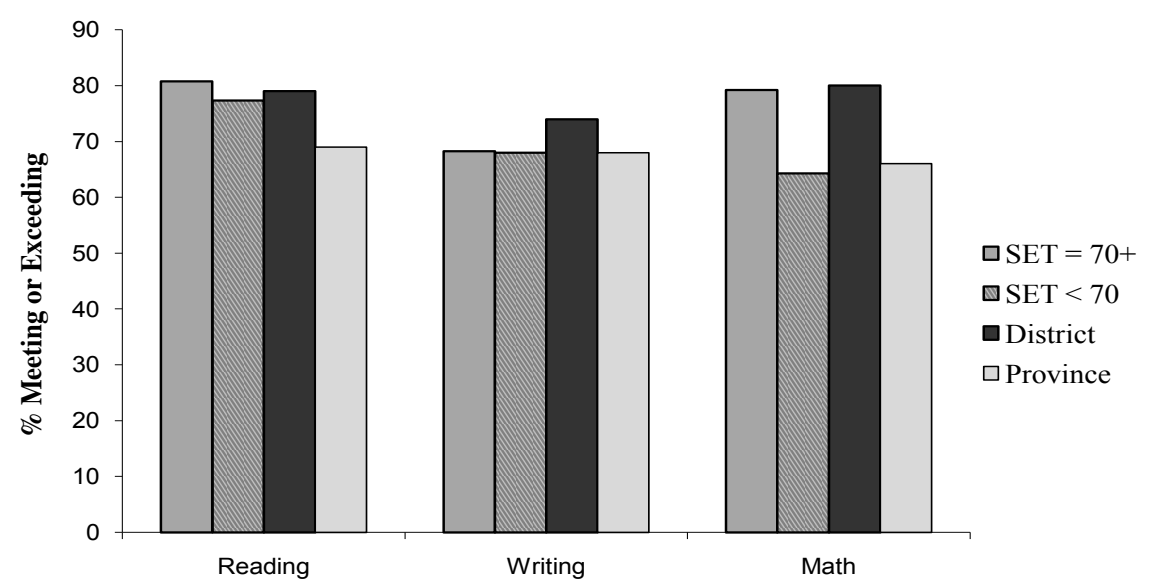

Figure 3. Academic achievement results showing percent of Grade 4 students meeting or exceeding expectations in moderate to high fidelity SWPBS schools, low fidelity schools, the district, and the province. 
McIntosh et al.

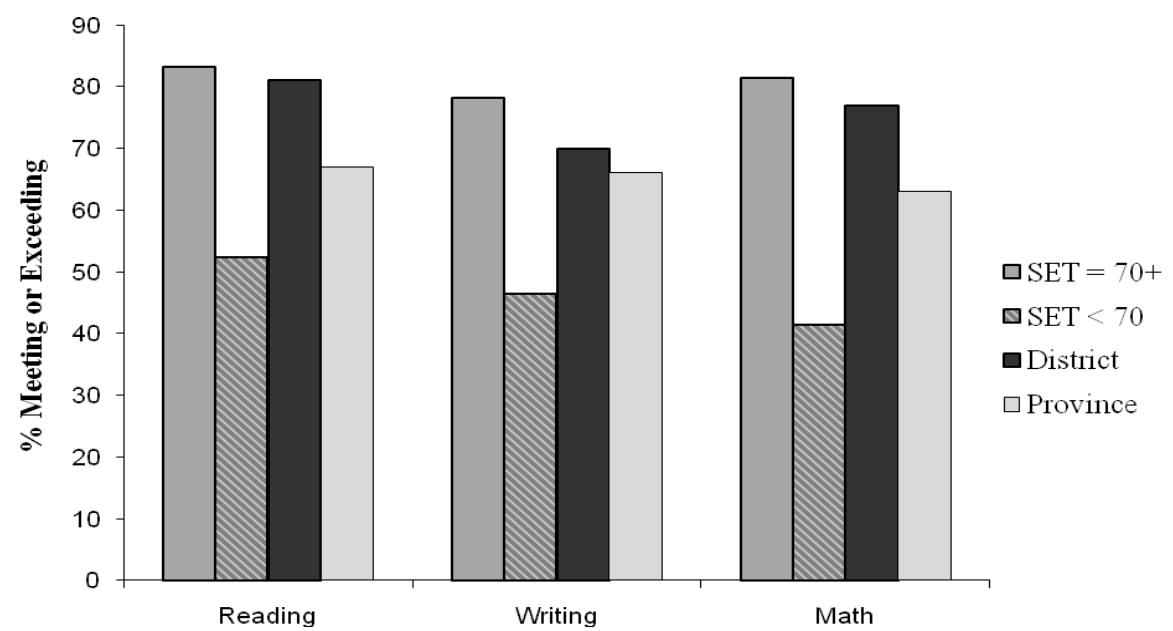

Figure 4. Academic achievement results showing percent of Grade 7 students meeting or exceeding expectations in moderate to high fidelity SWPBS schools, low fidelity schools, the district, and the province.

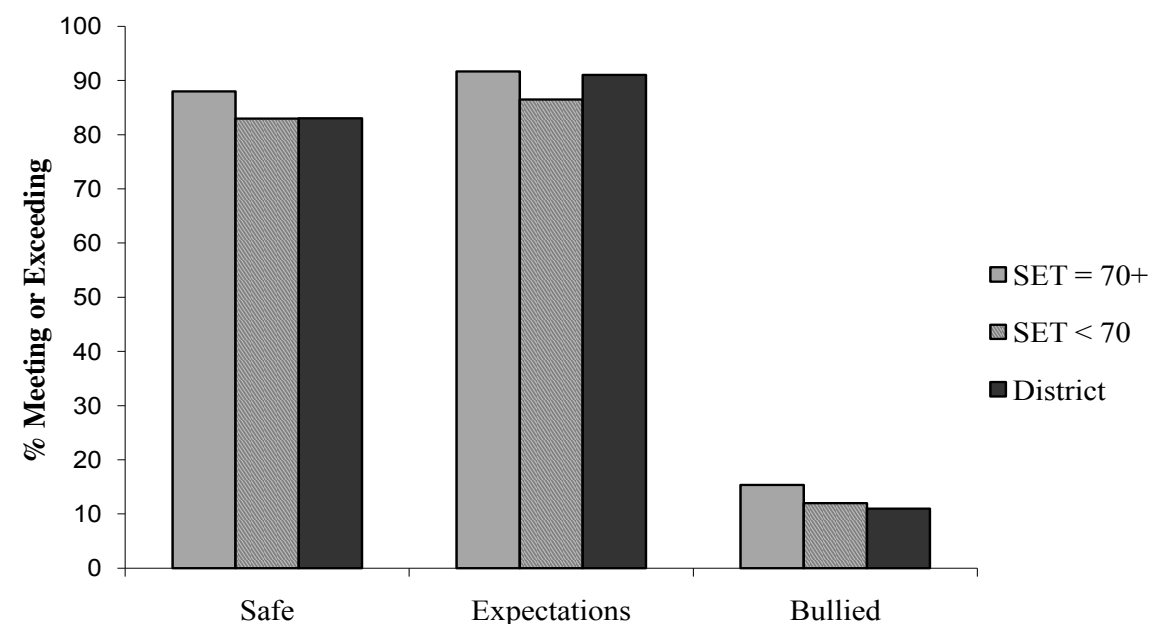

Figure 5. Student perceptions survey results for percent of Grade 4 students responding "Many times" or "All of the time" to the three survey questions in moderate to high fidelity SWPBS schools, low fidelity schools, and the district. Safe= Do you feel safe at school? Expectations= Do you know how your school expects students to behave? Bullied=At school, are you bullied, teased, or picked on?

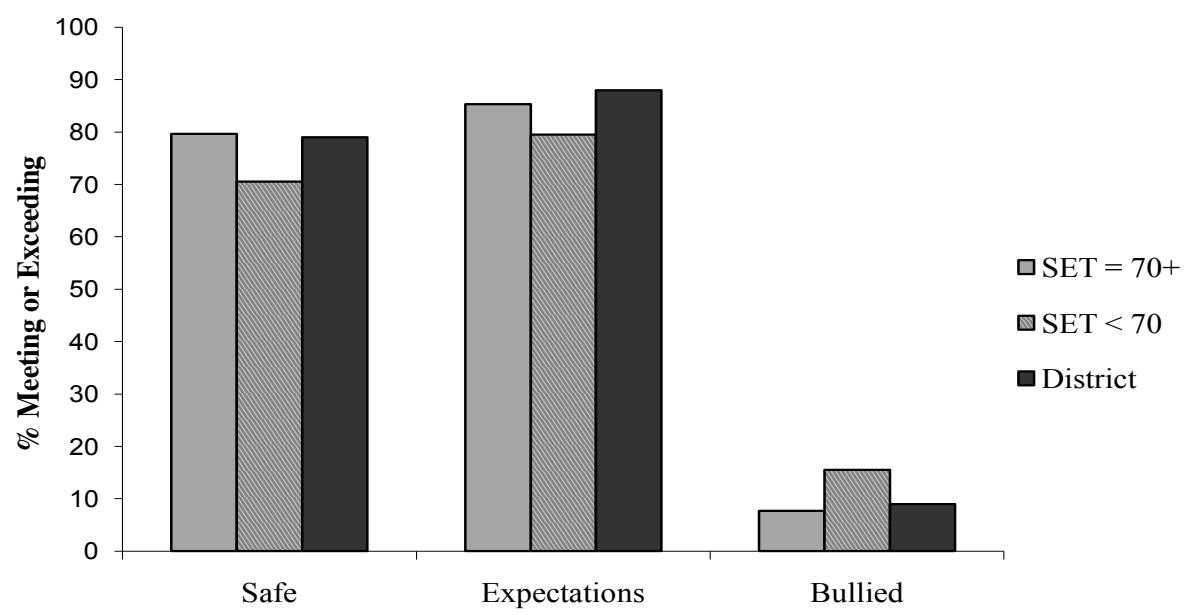

Figure 6. Student perceptions survey results for percent of Grade 7 students responding "Many times," or "All of the time," to the three survey questions in moderate to high fidelity schools, low fidelity schools, and the district. Safe= Do you feel safe at school? Expectations= Do you know how your school expects students to behave? Bullied=At school, are you bullied, teased, or picked on? 
somewhat higher ratings of bullying than Grade 4 students at low fidelity schools and the district with two exceptions. In Grade 4, students at moderate to high fidelity SWPBS schools reported average. In Grade 7, students in moderate to high fidelity schools reported clear expectations at lower rates than the district average but higher than low fidelity schools.

\section{Discussion}

The purpose of this study was to demonstrate the creation and use of a district SWPBS evaluation plan to measure systems, implementation, and student outcomes. Results of the district evaluation show that there were many supports in place to promote the successful implementation of SWPBS, including training, coaching, and an active district leadership team. Fidelity of implementation results showed that most of the schools were implementing SWPBS with moderate to high fidelity. Evaluation of student outcomes showed a decrease in the level of ODRs and the percent of students requiring additional behaviour support. In general, students at moderate to high fidelity SWPBS schools had higher academic achievement and rated their schools as more safe than students at low fidelity schools and the district average.

\section{Fidelity of Implementation}

As noted, the fidelity of implementation scores showed that most schools had moderate to high implementation of SWPBS. Some schools were only partially implementing SWPBS, and these schools did not achieve the same outcomes as those that fully implemented. This information provides further evidence that positive outcomes can only be assured with full implementation. A descriptive analysis of the fidelity data for the three schools that were partially implementing SWPBS shows that two of the schools did not implement any kind of formal acknowledgement system to recognize prosocial behaviour. Because these systems can help staff increase the ratio of positive to negative student-teacher interactions, the lack of these systems may have contributed to diminished social and academic outcomes.

These results can allow the district to focus on increasing implementation in low fidelity schools and using the moderate to high fidelity schools as examples for models of successful implementation. The district leadership team can use this information to provide targeted support to schools that have yet to implement all of the core components of SWPBS. School personnel who have reservations about the use of formal acknowledgement systems may find them more acceptable when they see local data indicating that such systems can enhance student outcomes. In addition, the results provide the district with a formative record of implementation, and fidelity in following years can be re-evaluated and compared to previous years.

\section{Student Outcomes}

The results show that implementation of SWPBS was related to enhanced outcomes in problem behaviour, academic achievement, and perceptions of school safety. An important outcome was that $90 \%$ of students were adequately supported by the school-wide systems. This result shows not only that more students were on track for positive behaviour outcomes, but also that the number of students requiring additional behaviour support was reduced to a more manageable number. As a result, the intensive resources needed to support students with behaviour needs could be dedicated to the students who need it most. 
Another key finding was that community risk factors were less of a factor for schools implementing SWPBS well. Across the district, the percent of families living in poverty were higher for SWPBS schools, and highest in moderate to high fidelity schools. These data suggest two conclusions. First, community differences in poverty did not account for the different outcomes observed. Counter to what might be expected, students at schools with more risk had better outcomes. Second, SWPBS appears to hold particular promise in increasing school safety, decreasing risk, and raising achievement for students who come from high poverty communities. These results may be particularly salient for educators seeking solutions to close the achievement gap between high and low poverty schools.

The results also provide areas for improvement for the district as well. In particular, Grade 4 students in moderate to high fidelity schools reported slightly higher feelings of being bullied than the district average, though the opposite was true in Grade 7. These data are useful to the district team and its schools in identifying specific targets for improvement in schools. Yet, overall, these results provide the district with both evidence of effectiveness of SWPBS on problem behaviour, academic achievement, and perceptions of school safety and areas for further professional development. These results are encouraging and show that when implemented with fidelity, SWPBS improved behaviour, achievement, and school safety in this district.

\section{Limitations}

A number of limitations must be considered before implications for practice can be discussed. First, the small sample size precluded the use of statistical analyses. Second, because the district SWPBS initiative had been in place for over ten years, consistent data before implementation were not available for pre-post comparisons. Third, the student perceptions were measured with single items, providing less assurance of reliability and validity than if multiple-item measures were used. And finally, the results were obtained from one school district, and therefore the results may not be generalizable to school districts with different demographics. Certainly, fidelity of implementation and student outcomes from SWPBS should be continuously measured in other districts to assess its effectiveness elsewhere.

\section{Implications for Practice}

Too often in today's schools educational practices are adopted by purchasing a curriculum or program manual, implementing initial training, and hoping for implementation to take place. Unfortunately, this approach may lead to initial but unsustainable implementation (Joyce \& Showers, 1980; McIntosh, Horner et al., 2009). True sustainability requires thoughtful planning on the part of school, district, and provincial leadership teams (McIntosh, Filter, Bennett, Ryan, \& Sugai, 2010).

The results of this study indicate that educators can take two critical steps to enhance continued implementation and enhanced student outcomes. First, school and district teams can invest in evidence-based practices, such as SWPBS, that have demonstrated effectiveness in a range of important outcomes and have been successfully implemented by school personnel in diverse schools. To our knowledge, this evaluation study provides the first published evidence of the effectiveness of SWPBS outside of schools in the United States. The results indicate that schools that were implementing SWPBS with higher fidelity showed higher levels of academic achievement and had higher ratings of perceived school safety. As a result, school personnel in 
Canada and elsewhere can feel more confident that implementing SWPBS to criterion is likely to enhance student outcomes.

The second step that teams can take is to use evaluation plans to assess and sustain important educational initiatives. This article showed the development and use of an evaluation plan to document systems, demonstrate implementation, and show enhanced student outcomes as a result of implementing SWPBS. This district example illustrates how a common evaluation plan for a province can be utilized by a district to answer specific evaluation questions. The most powerful benefit of evaluation is establishing a feedback loop for continuous improvement, so that measurement of implementation enhances fidelity, which in turn enhances student outcomes. When student outcomes are measured, these results provide motivation for continued fidelity of implementation (McIntosh et al., 2010). Continued evaluation in the future will allow this district to monitor whether valued outcomes are being achieved and how to sustain SWPBS.

\section{References}

Algozzine, B., Horner, R., Sugai, G., Barrett, S., Dickey, S., \& Eber, L. (2010). Evaluation blueprint for school-wide positive behavior support. Retrieved from www.pbis.org

Bennett, J. L., \& McIntosh, K. (2011). Effects of school-wide positive behaviour support on teacher selfefficacy. Manuscript submitted for publication.

Bradshaw, C. P., Koth, K., Bevans, K. B., Ialongo, N., \& Leaf, P. J. (2008). The impact of school-wide positive behavioral interventions and supports on the organizational health of elementary schools. School Psychology Quarterly, 23, 462-473. doi:10.1037/a0012883

Bradshaw, C. P., Mitchell, M. M., \& Leaf, P. J. (2010). Examining the effects of school-wide positive behavioral interventions and supports on student outcomes: Results from a randomized controlled effectiveness trial in elementary schools. Journal of Positive Behavior Interventions, 12, 133-148. doi:10.1177/1098300709334798

British Columbia Ministry of Education. (2007). Satisfaction survey: Questions and answers. Retrieved from http://www.bced.gov.bc.ca/sat_survey/faqs.htm

British Columbia Ministry of Education. (2008). FSA 2008 technical notes. Retrieved from http://www.bced.gov.bc.ca/

Chapman, D., \& Hofweber, C. (2000). Effective behavior support in British Columbia. Journal of Positive Behavior Interventions, 2, 235-237. doi:10.1177/109830070000200409

Day, D. M., Golench, C. A., MacDougal, J., \& Beals-Gonzalez, C. A. (2002). School-based violence prevention in Canada: Results of a national survey of policies and programs, 1995-2002. Ottawa, ON: Ministry of the Solicitor General of Canada.

Epstein, M. H., \& Sharma, J. (1998). Behavioral and emotional rating scale: A strength-based approach to assessment. Austin, TX: Pro-Ed.

George, H., \& Kincaid, D. (2008). Building district-level capacity for positive behavior support. Journal of Positive Behavior Interventions, 10, 20. doi:10.1177/1098300707311367

Gresham, F. M. (1989). Assessment of treatment integrity in school consultation and prereferral intervention. School Psychology Review, 18, 37-50.

Gresham, F. M., \& Elliott, S. N. (1990). Social skills rating system. Circle Pines, MN: American Guidance Service.

Hemphill, S. A., Toumbourou, J. W., Herrenkohl, T. I., McMorris, B. J., \& Catalano, R. F. (2006). The effect of school suspensions and arrests on subsequent adolescent antisocial behavior in Australia and the United States. Journal of Adolescent Health, 39, 736-744. doi: 10.1016/j.jadohealth.2006.05.010

Horner, R. H., Sugai, G., \& Lewis-Palmer, T. L. (2005). School-wide positive behavior support evaluation template. Eugene, OR: Educational and Community Supports.

Horner, R. H., Sugai, G., Smolkowski, K., Eber, L., Nakasato, J., \& Todd, A. W. (2009). A randomized, waitlist controlled effectiveness trial assessing school-wide positive behavior support in elementary schools. Journal of Positive Behavior Interventions, 11, 133-144. doi: 10.1177/1098300709332067 
Horner, R. H., Sugai, G., Todd, A. W., \& Lewis-Palmer, T. (2005). School-wide positive behavior support. In L. Bambara \& L. Kern (Eds.), Individualized supports for students with problem behaviors: Designing positive behavior plans (pp. 359-390). New York, NY: Guilford Press.

Horner, R. H., Todd, A. W., Lewis-Palmer, T., Irvin, L. K., Sugai, G., \& Boland, J. B. (2004). The Schoolwide Evaluation Tool (SET): A research instrument for assessing school-wide positive behavior support. Journal of Positive Behavior Interventions, 6, 3-12. doi: 10.1177/10983007040060010201

Hoy, W. K., \& Feldman, J. (1987). Organizational health: The concept and its measure. Journal of Research and Development in Education, 20, 30-38.

Irvin, L. K., Tobin, T. J., Sprague, J. R., Sugai, G., \& Vincent, C. G. (2004). Validity of office discipline referral measures as indices of school-wide behavioral status and effects of school-wide behavioral interventions. Journal of Positive Behavior Interventions, 6, 131-147. doi: $10.1177 / 10983007040060030201$

Joyce, B., \& Showers, B. (1980). Improving inservice training: The age of research. Educational Leadership, 37, 379-385.

Lassen, S. R., Steele, M. M., \& Sailor, W. (2006). The relationship of school-wide positive behavior support to academic achievement in an urban middle school. Psychology in the Schools, 43, 701-712. doi:10.1002/pits.20177

Lewis, T. J., \& Sugai, G. (1999). Effective behavior support: A systems approach to proactive schoolwide management. Focus on Exceptional Children, 31, 1-24.

Malecki, C., \& Elliot, S. (2002). Children's social behaviors as predictors of academic achievement: A longitudinal analysis. School Psychology Quarterly, 17, 1-23. doi:10.1521/scpq.17.1.1.19902

Markow, D., Moessner, C., \& Horowitz, H. (2006). The MetLife survey of the American teacher, 2005-2006: Expectations and experiences. New York, NY: MetLife Insurance Company. Available at http://www.metlife.org.

May, S., Ard, W. I., Todd, A. W., Horner, R. H., Glasgow, A., \& Sugai, G. (2008). School-Wide Information System. Eugene, OR: Educational and Community Supports, University of Oregon.

Mayer, G. R. (1995). Preventing antisocial behavior in the schools. Journal of Applied Behavior Analysis, 28, 467-478. doi:10.1901/jaba.1995.28-467

McIntosh, K. (2008). The BC School-wide positive behaviour dupport evaluation framework. Vancouver, BC: University of British Columbia. Available at bcpbs.wordpress.com

McIntosh, K., Campbell, A. L., Carter, D. R., \& Zumbo, B. D. (2009). Concurrent validity of office discipline referrals and cut points used in schoolwide positive behavior support. Behavioral Disorders, 34, 100113.

McIntosh, K., Filter, K. J., Bennett, J. L., Ryan, C., \& Sugai, G. (2010). Principles of sustainable prevention: Designing scale-up of school-wide positive behavior support to promote durable systems. Psychology in the Schools, 47, 5-21. doi:10.1002/pits.20448

McIntosh, K., Frank, J. L., \& Spaulding, S. A. (2010). Establishing research-based trajectories of office discipline referrals for individual students. School Psychology Review, 39, 380-394.

McIntosh, K., Horner, R. H., \& Sugai, G. (2009). Sustainability of systems-level evidence-based practices in schools: Current knowledge and future directions. In W. Sailor, G. Dunlap, G. Sugai, \& R. H. Horner (Eds.), Handbook of positive behavior support (pp. 327-352). New York, NY: Springer.

McIntosh, K., Reinke, W. M., \& Herman, K. E. (2009). School-wide analysis of data for social behavior problems: Assessing outcomes, selecting targets for intervention, and identifying need for support. In G. G. Peacock, R. A. Ervin, E. J. Daly, \& K. W. Merrell (Eds.), The practical handbook of school psychology (pp. 135-156). New York, NY: Guilford.

McKevitt, B., \& Braaksma, A. (2008). Best practices in developing a positive behavior support system at the school level. In A. Thomas \& J. P. Grimes (Eds.), Best practices in school psychology V, (pp. 735748). Bethesda, MD: National Association of School Psychologists.

Menendez, A. L., Payne, L. D., \& Mayton, M. R. (2008). The implementation of positive behavioral support in an elementary school: Processes, procedures, and outcomes. Alberta Journal of Educational Research, $54,448-462$.

Nelson, J. R. (1996). Designing schools to meet the needs of students who exhibit disruptive behavior. Journal of Emotional and Behavioral Disorders, 4, 147-161. doi:10.1177/106342669600400302 
Nelson, J. R., Martella, R. M., \& Marchand-Martella, N. (2002). Maximizing student learning: The effects of a comprehensive school-based program for preventing problem behaviors. Journal of Emotional and Behavioral Disorders, 10, 136-148.

Reynolds, C. R., \& Kamphaus, R. W. (2004). Behavior Assessment Scale for Children (2nd ed.). Circle Pines, MN: AGS Publishing.

Ross, S. W., \& Horner, R. H. (2006). Teacher outcomes of school-wide positive behavior support. Teaching Exceptional Children Plus, 3. Retrieved from http://escholarship.bc.edu/education/tecplus/vol3/iss6 /art6

Scott, T. M. (2001). A schoolwide example of positive behavioral support. Journal of Positive Behavior Interventions, 3, 88-94. doi:10.1177/109830070100300205

Skiba, R. J., Michael, R. S., Nardo, A. C., \& Peterson, R. L. (2002). The color of discipline: Sources of racial and gender disproportionality in school punishment. The Urban Review, 34, 317-342. doi: 10.1023/A:1021320817372

Skiba, R. J., Peterson, R. L., \& Williams, T. (1997). Office referrals and suspensions: Disciplinary intervention in middle schools. Education and Treatment of Children, 20, 295-315.

Sugai, G., \& Horner, R. H. (2009). Defining and describing schoolwide positive behavior support. In W. Sailor, G. Sugai, R. H. Horner, \& G. Dunlap (Eds.), Handbook of positive behavior support (pp. 307326). New York, NY: Springer.

Sugai, G., Horner, R. H., Sailor, W., Dunlap, G., Eber, L., \& Lewis, T. J. (2005). School-wide positive behavior support: Implementers' blueprint and self-assessment. Eugene, OR: University of Oregon.

Sugai, G., Horner, R. H., \& Todd, A. W. (2000). Effective Behavior Support Self-Assessment Survey 2.0. Eugene, OR: Educational and Community Supports. Available at http://www.pbis.org.

Sugai, G., Lewis-Palmer, T. L., Todd, A. W., \& Horner, R. H. (2001). School-wide Evaluation Tool (SET). Eugene, OR: Educational and Community Supports. Available at http://www.pbis.org.

Taylor-Greene, S., Brown, D., Nelson, L., Longton, J., Gassman, T., \& Cohen, J. (1997). School-wide behavioral support: Starting the year off right. Journal of Behavioral Education, 7, 99-112. doi: 10.1023/A:1022849722465

Turnbull, A., Edmonson, H., Griggs, P., Wickham, D., Sailor, W., \& Freeman, R. (2002). A blueprint for schoolwide positive behavior support: Implementation of three components. Exceptional Children, 68, 377-403.

Walker, B., Cheney, D., Stage, S. A., \& Blum, C. (2005). Schoolwide screening and positive behavior supports: Identifying and supporting students at risk for school failure. Journal of Positive Behavior Interventions, 7, 194-204. doi:10.1177/10983007050070040101

Walker, H. M., Horner, R. H., Sugai, G., Bullis, M., Sprague, J. R., \& Bricker, D. (1996). Integrated approaches to preventing antisocial behavior patterns among school-age children and youth. Journal of Emotional and Behavioral Disorders, 4, 194-209. doi:10.1177/106342669600400401

\section{Authors' Note}

Correspondence concerning this article should be addressed to Kent McIntosh, University of British Columbia, 2125 Main Mall, Vancouver, BC V6T 1Z4. E-mail: kent.mcintosh@ubc.ca 